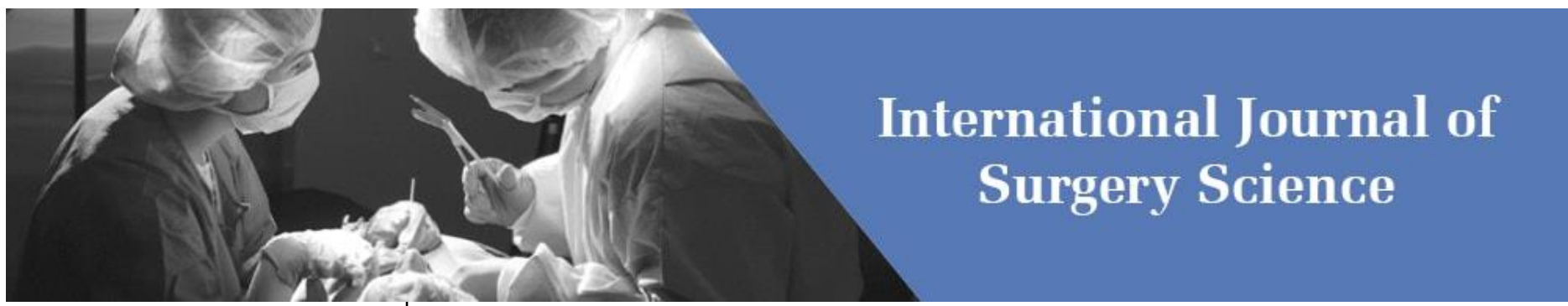

E-ISSN: 2616-3470

P-ISSN: 2616-3462

(C) Surgery Science

www.surgeryscience.com

2019; 3(1): 183-187

Received: 01-11-2018

Accepted: 05-12-2018

Amit Kumar C Jain

Assistant Professor, Department of Surgery, St John's Medical College,

Bangalore, Karnataka, India

Viswanath S

Associate Professor, Department of Surgery, St John's Medical College, Bangalore, Karnataka, India
Correspondence

Amit Kumar C Jain

Assistant Professor, Department of Surgery, St John's Medical College,

Bangalore, Karnataka, India

\section{A study of diabetic foot patients in a tertiary care premier teaching hospital}

\section{Amit Kumar C Jain and Viswanath S}

DOI: https://doi.org/10.33545/surgery.2019.v3.i1d.31

Abstract

Aim: To analyze diabetic foot patients treated in surgical ward of tertiary care teaching hospital and evaluate the surgical outcomes.

Methods \& Materials: A descriptive retrospective analysis was carried out in Department of Surgery of St John's Medical College, Bangalore, India. The study period was from July 2014 to December 2014. Statistical analysis was done using SPSS 18.0. The study was approved by the institution ethics committee. Results: A total of 30 male patients were studied. Right foot was most commonly affected in $63.5 \%$ of the cases. Type 1 diabetic foot complications were the most common complications in this study accounting for $76.7 \%$ followed by type 3 diabetic foot complication (20\%). The most common lesion seen was Wet gangrene $(40 \%)$ followed by abscess $(20 \%)$ both of which accounted for $60 \%$ of the cases and belonged to type 1 diabetic foot complication $(P<0.001)$. Toe amputation was the commonest surgical procedure done. Wet gangrene accounted for $50 \%$ of amputation ( $\mathrm{P}=0.017$, statistically significant). Most cases were operated by junior team members of the surgical units. There was one mortality in this study.

Conclusion: Diabetic foot is a serious complication of diabetes mellitus and is often a neglected entity. Our study showed that Amit Jain's type 1 diabetic foot complication, which are acute in nature and infective complication, are the most common cause of hospitalization in teaching hospital. Majority surgeries are performed on them in late evening as emergencies.

Keywords: Diabetic foot, Amit Jain, amputation, gangrene, ulcer

\section{Introduction}

Diabetes mellitus is a serious complex disease that occurs globally with a reported prevalence of $4-6.5 \%{ }^{[1,2]}$. It affects almost all vital organs of the body leading to increase morbidity and mortality ${ }^{[1,3]}$.

Foot problems remain one of the disturbing complications and are common cause of hospitalization in diabetic patients ${ }^{[2,4]}$.

Around $15-20 \%$ of patients with diabetes will develop foot ulcer during their lifetime ${ }^{[1,4,5,6]}$ These ulcers are likely to be chronic, recur and can get infected thereby leading to amputation ${ }^{[1,}$ ${ }^{2]}$. There is a well-known difference in diabetic foot geographically and also among different cities and hospitals.

We conducted a descriptive study in our hospital on diabetic foot to analyze how it is dealt and to study various different outcomes.

\section{Methods and Materials}

A retrospective descriptive study was conducted in department of surgery at St John's medical college, Bangalore, India. This is a tertiary care premiere teaching hospital. There are 4 different functional surgical units in surgery department. The study period was from July 2014 to December 2014. The following are the inclusion and exclusion criteria.

\section{Inclusion criteria}

1. All the patients admitted and treated in male surgical ward in 3 different surgical units of the department. This ward was chosen as there were well maintained register and most diabetic foot patients are admitted in this ward. 


\section{Exclusion criteria}

1. Patients admitted and treated in other departments or private wards.

2. Patients from author's surgical unit.

3. Patients who refused treatment

4. Patients with incomplete records/data needed for the study This study was approved by the institutional ethics committee [IEC STUDY No 12/2015]

Data analysis: ${ }^{[7,8,9,10]}$ Data was analyzed using statistical software SPSS 18.0 and R environment Ver.3.2.2. Microsoft word and excel were used for general graphs and tables. Both descriptive and inferential statistical analysis was carried out in this study. Results on continuous measurements are presented on Mean SD (Min-Max) and results on categorical measurements are presented in Number (\%). Significance is assessed at 5\% level of significance.

\section{The following assumption on data is made}

- Dependent variables should be normally distributed,

- Samples drawn from the population should be random

- Cases of the samples should be independent

Chi-square/Fisher Exact test has been used to find the significance of study parameters on categorical scale between two or more groups, Non-parametric setting for Qualitative data analysis. Fisher exact test was used when samples were very small.

\section{Significant figures}

+ Suggestive significance ( $\mathrm{P}$ value: $0.05<P<0.10)$

* Moderately significant (P value: $0.01<\mathrm{P} 0.05$ )

** Strongly significant ( $\mathrm{P}$ value: $P \leq 0.01)$.

\section{Results}

Around 30 patients were included in this study from male general ward. The age range was from 40 to 70 years [Figure 1] with mean age of $57.87 \pm 13.15$.

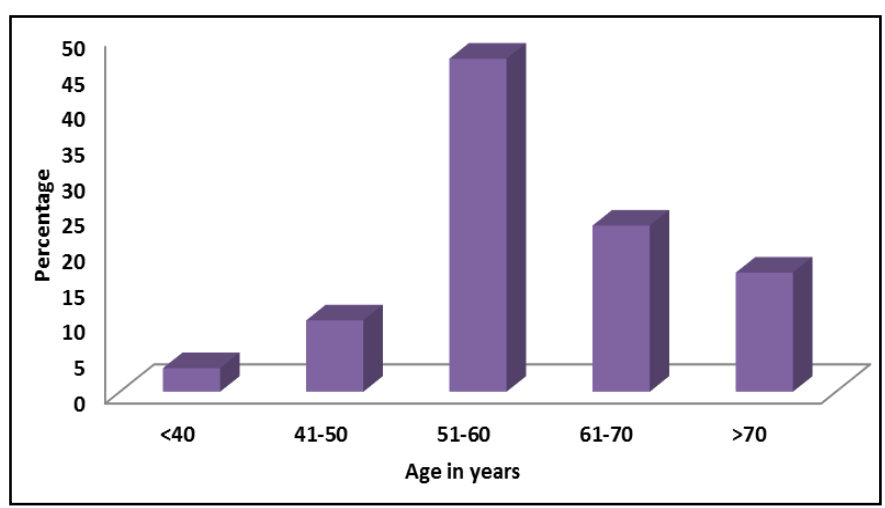

Fig 1: Showing age distribution

Right foot was affected in $63.5 \%$ of the cases [Table 1].

Table 1: Showing the side of foot affected

\begin{tabular}{|c|c|c|}
\hline Side of foot & Number & percentage \\
\hline Right & 19 & 63.3 \\
\hline Left & 11 & 36.7 \\
\hline
\end{tabular}

Type 1 diabetic foot complication were the most common complication [Table 2] in this study accounting for $76.7 \%$ followed by type 3 diabetic foot complication (20\%).
Table 2: Showing the distribution of cases according to Amit Jain's classification for diabetic foot complication

\begin{tabular}{|c|c|c|}
\hline Types of Diabetic foot complication & Number & Percentage \\
\hline Type 1 Diabetic foot complication & 23 & 76.7 \\
\hline Type 2 Diabetic foot complication & 1 & 3.3 \\
\hline Type 3 Diabetic foot complication & 6 & 20.0 \\
\hline Total & 30 & 100 \\
\hline
\end{tabular}

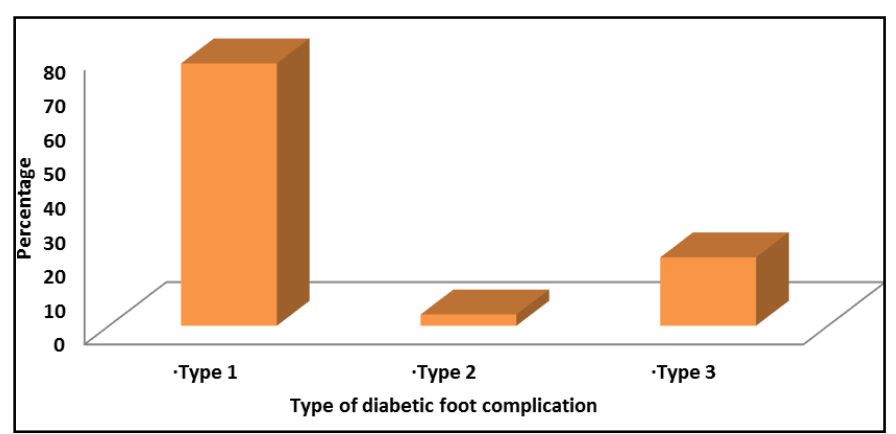

Fig 2: Showing the distribution of cases according to Amit Jain's classification for diabetic foot complication

Wet gangrene was the most common pathological lesion seen (40\%) followed by abscess $(20 \%)$ both of which accounted for $60 \%$ of the cases [Table 3] and belonged to type 1 diabetic foot complication $(P<0.001)$.Few patients were admitted as infected ulcers who had undergone incision and drainage few days earlier at another hospital. Their discharge summary showed diagnosis of an abscess and such cases were categorized by us in type 1 diabetic foot complications [Figure 2]. Many of them wrongly assume it to be infected trophic ulcers.

Table 3: Showing the distribution of pathological lesions

\begin{tabular}{|c|c|c|c|c|c|}
\hline \multirow{2}{*}{ variables } & \multicolumn{3}{|c|}{$\begin{array}{l}\text { Type of diabetic foot } \\
\text { complication }\end{array}$} & \multirow{2}{*}{$\begin{array}{l}\text { Total } \\
(\mathbf{n}=\mathbf{3 0})\end{array}$} & \multirow{2}{*}{$\begin{array}{c}\mathbf{P} \\
\text { value }\end{array}$} \\
\hline & $\begin{array}{l}\text { Type } 1 \\
(\mathrm{n}=23)\end{array}$ & $\begin{array}{c}\text { Type } 2 \\
(\mathrm{n}=1)\end{array}$ & $\begin{array}{c}\text { Type } 3 \\
(n=6)\end{array}$ & & \\
\hline \multicolumn{6}{|l|}{ Diagnosis } \\
\hline Abscess & $6(26.1 \%)$ & $0(0 \%)$ & $0(0 \%)$ & $6(20 \%)$ & \multirow{6}{*}{$\begin{array}{c}<0.001 \\
* *\end{array}$} \\
\hline Wet gangrene & $12(52.2 \%)$ & $0(0 \%)$ & $0(0 \%)$ & $12(40 \%)$ & \\
\hline Necrotizing fasciitis & $1(4.3 \%)$ & $0(0 \%)$ & $0(0 \%)$ & $1(3.3 \%)$ & \\
\hline Cellulitis & $4(17.4 \%)$ & $0(0 \%)$ & $0(0 \%)$ & $4(13.3 \%)$ & \\
\hline Dry gangrene & $0(0 \%)$ & $1(100 \%)$ & $0(0 \%)$ & $1(3.3 \%)$ & \\
\hline $\begin{array}{l}\text { Infected ulcers } \\
\text { [Trophic] }\end{array}$ & $0(0 \%)$ & $0(0 \%)$ & $4(66.7 \%)$ & $4(13.3 \%)$ & \\
\hline $\begin{array}{c}\text { Infected ulcer }\{\text { Trophic }\} \\
\text { with gangrene }\end{array}$ & $0(0 \%)$ & $0(0 \%)$ & $2(33.3 \%)$ & $2(6.7 \%)$ & \\
\hline
\end{tabular}

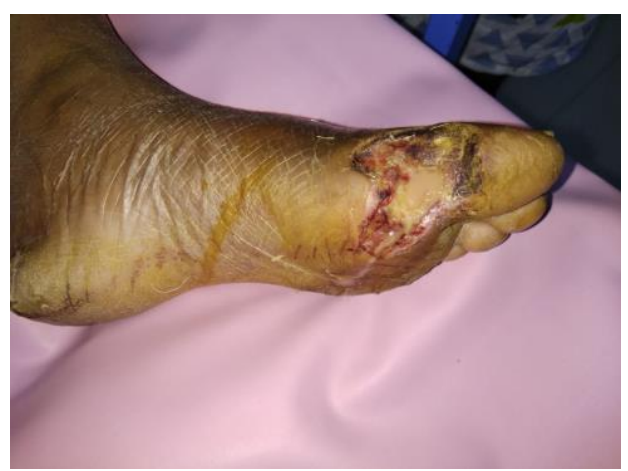

Fig 3: Showing a patient admitted with infected ulcer. These patients are wrongly assumed as infected trophic ulcer. This patient had undergone incision and drainage for abscess over left foot just a few days ago at another hospital. He was admitted at our hospital with nonhealing wound and pus discharge. This patient is categorized in Type 1 diabetic foot complication. 
Around $20 \%$ of patient had infected trophic ulcer. 3 patients $(10 \%)$ had underlying osteomyelitis and $6.6 \%$ had peripheral arterial disease. Around $80 \%$ of patients had some form of amputation being done [Table 4].

Table 4: Showing amputations done

\begin{tabular}{|c|c|c|}
\hline Amputation performed & Number & Percentage \\
\hline Yes & 24 & 80.0 \\
\hline No & 6 & 20.0 \\
\hline Total & 30 & $100 \%$ \\
\hline
\end{tabular}

The most common surgical procedure that was performed was toe amputation [43.3\%]. $20 \%$ of the patients underwent major amputation [Table 5].

Table 5: Showing distribution of surgeries done.

\begin{tabular}{|c|c|c|}
\hline Surgery Done & Number & Percentage \\
\hline Debridement & 5 & 16.7 \\
\hline Toe amputation & 13 & 43.3 \\
\hline TMT & 5 & 16.7 \\
\hline BKA & 5 & 16.7 \\
\hline AKA & 1 & 3.3 \\
\hline Conservative & 1 & 3.3 \\
\hline Total & 30 & $100 \%$ \\
\hline
\end{tabular}

Wet gangrene accounted for $50 \%$ of amputation $(\mathrm{P}=0.017$, statistically significant) [Table 6].

Table 6: Showing amputation being done or not for different pathological lesions [*significant]

\begin{tabular}{|c|c|c|c|c|}
\hline \multirow{2}{*}{ Diagnosis } & \multicolumn{2}{|c|}{ Amputation } & \multirow{2}{*}{ Total } & \multirow{2}{*}{ P value } \\
\hline & No & Yes & & \\
\hline Abscess & $1(16.7 \%)$ & $5(20.8 \%)$ & $6(20 \%)$ & \multirow{8}{*}{$\mathrm{P}=0.017^{*}$} \\
\hline Wet gangrene & $0(0 \%)$ & $12(50 \%)$ & $12(40 \%)$ & \\
\hline Necrotizing fasciitis & $0(0 \%)$ & $1(4.2 \%)$ & $1(3.3 \%)$ & \\
\hline Cellulitis & $3(50 \%)$ & $1(4.2 \%)$ & $4(13.3 \%)$ & \\
\hline Dry gangrene & $1(16.7 \%)$ & $0(0 \%)$ & $1(3.3 \%)$ & \\
\hline Infected ulcer & $1(16.7 \%)$ & $3(12.5 \%)$ & $4(13.3 \%)$ & \\
\hline Infected ulcer with gangrene & $0(0 \%)$ & $2(8.3 \%)$ & $2(6.7 \%)$ & \\
\hline Total & $6(100 \%)$ & $24(100 \%)$ & $30(100 \%)$ & \\
\hline
\end{tabular}

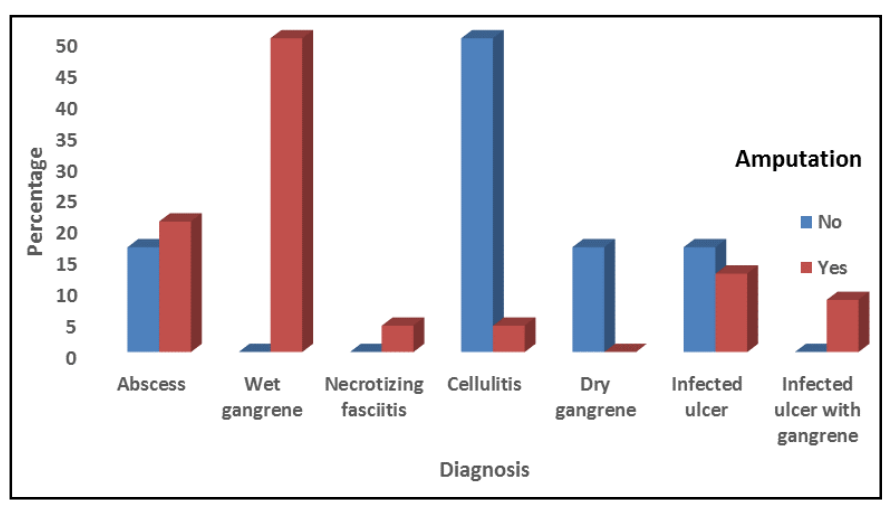

Fig 4: showing distribution of amputation done in different pathological lesions

Majority of the patients $(90 \%)$ underwent emergency surgery [Figure 4] with $73.3 \%$ of the patients being operated within 24 hours [Table 7] and $56.7 \%$ of patients surgeries being done between $5 \mathrm{pm}$ to $11.59 \mathrm{pm}$ [Table 8]. $20 \%$ of the patients had surgeries being done between 12.01am to 9am. There was no significant association of timing of surgery in relation to amputation done $(\mathrm{P}=0.167)$.

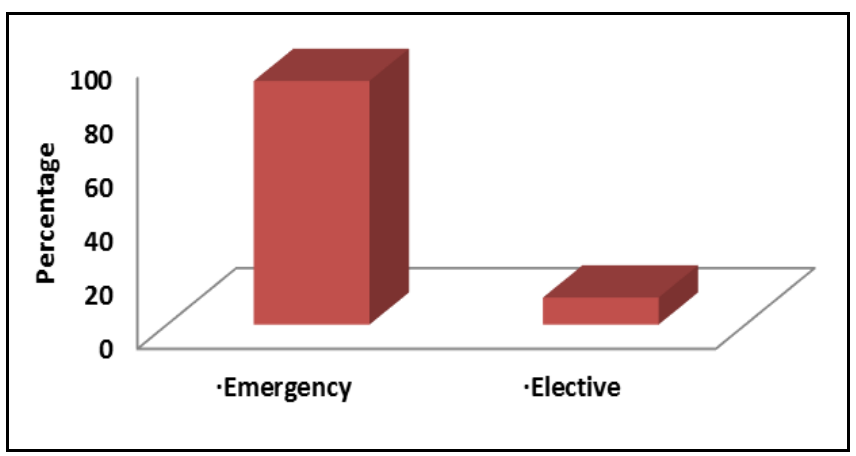

Fig 5: showing distribution of cases among elective versus emergency surgery

Table 7: Showing Date of Surgery distribution of patients

\begin{tabular}{|c|c|c|}
\hline Date of Surgery & No. of patients & \% \\
\hline Within 24 hours & 22 & 73.3 \\
\hline 1-3 days & 6 & 20.0 \\
\hline More than 3 days & 2 & 6.7 \\
\hline Total & 30 & 100.0 \\
\hline
\end{tabular}

Table 8: Showing the timing of surgery

\begin{tabular}{|c|c|c|}
\hline Timing of Surgery & Number & Percentage \\
\hline 00.01AM -9AM & 6 & 20.0 \\
\hline 9.01AM - 5PM & 7 & 23.3 \\
\hline $5.01 \mathrm{PM}-11.59 \mathrm{PM}$ & 17 & 56.7 \\
\hline
\end{tabular}

Majority of diabetic foot cases were operated by postgraduate/ senior resident accounting for $86.7 \%$ followed by Lecturer/ Assistant professor (13.3\%). None of the diabetic foot cases were operated by Associate Professor/Professors [Table 9].

Table 9: Showing the type of surgeon doing the surgery

\begin{tabular}{|c|c|c|}
\hline Type of Surgeon operating & Number & Percentage \\
\hline Postgraduate/ SR & 26 & 86.7 \\
\hline Lecturer/AP & 4 & 13.3 \\
\hline Associate Professor/Professors & 0 & 0 \\
\hline Total & 30 & 100 \\
\hline
\end{tabular}

Majority of the patients $(46.7 \%)$ had diabetes between $6-12$ years duration [Table 10] with $63.3 \%$ of them having associated co- morbidities.

Table 10: Showing duration of diabetes mellitus

\begin{tabular}{|c|c|c|}
\hline Diabetes mellitus duration in years & Number & Percentage \\
\hline$<6$ & 7 & 23.3 \\
\hline $6-12$ & 14 & 46.7 \\
\hline $12-24$ & 7 & 23.3 \\
\hline$>24$ & 2 & 6.7 \\
\hline
\end{tabular}

$60 \%$ had hypertension, $16.7 \%$ had ischemic heart disease and $13.3 \%$ had retinopathy and CKD each. $30 \%$ of the patients had past history of amputation with toe amputation being the commonest [20\%]. $6.7 \%$ of patients already had a major amputation in the past.

$60 \%$ of the patients stayed in the hospital for less than a week 
and $13.3 \%$ of patients had to stay for more than 2 weeks [Table 11]. There was no relation between timing of surgery [Table 12 and Figure 12] with amputation $(\mathrm{P}=0.167)$

Table 11: showing hospitalization in day's distribution of patients studied

\begin{tabular}{|c|c|c|}
\hline Hospitalization in days & Number & Percentage \\
\hline Less than 7 days & 18 & 60.0 \\
\hline 8-14 days & 8 & 26.7 \\
\hline More than 2 weeks & 4 & 13.3 \\
\hline Total & 30 & 100.0 \\
\hline
\end{tabular}

Only 8 patients $(26.6 \%)$ had documented neuropathy/sensation being tested and $20 \%$ had contra lateral limb being examined. There were 12 patients who had wounds on plantar aspect (ulcer plus postoperative debrided wounds) and only one $(8.3 \%)$ of them received offloading (bohler iron cast). There was one mortality in this series.

Table 12: Showing timing of surgery in relation to amputation of patients studied

\begin{tabular}{|c|c|c|c|}
\hline \multirow{2}{*}{ Timing of Surgery } & \multicolumn{2}{|c|}{ Amputation } & \multirow{2}{*}{ Total } \\
\cline { 2 - 3 } & Yes & No & \\
\hline 00.01AM -9AM & $0(0 \%)$ & $6(25 \%)$ & $6(20 \%)$ \\
\hline 9.01AM -17PM & $3(50 \%)$ & $4(16.7 \%)$ & $7(23.3 \%)$ \\
\hline $17.01 \mathrm{PM}-23.59 \mathrm{PM}$ & $3(50 \%)$ & $14(58.3 \%)$ & $17(56.7 \%)$ \\
\hline Total & $6(100 \%)$ & $24(100 \%)$ & $30(100 \%)$ \\
\hline
\end{tabular}

$\mathrm{P}=0.167$, Not Significant, Fisher Exact Test

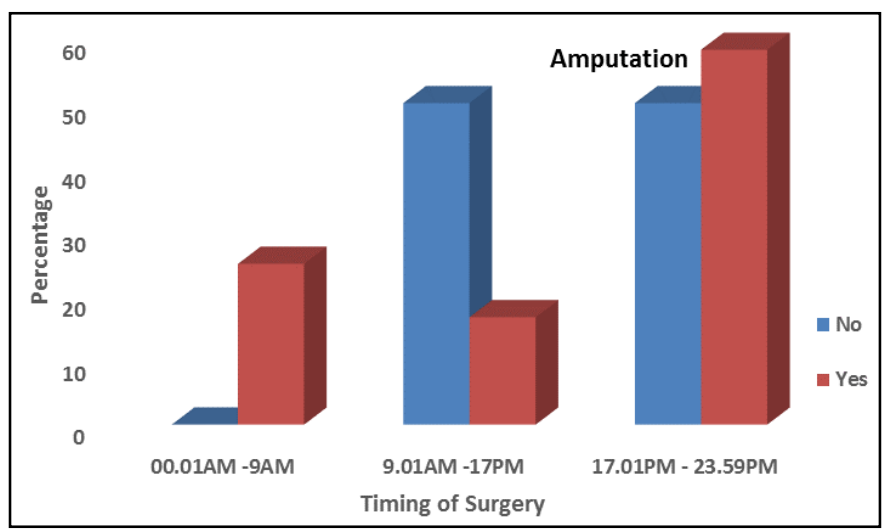

Fig 6: Showing relation between timing of surgery with amputation being done

\section{Discussion}

Diabetic foot is often a feared complication of diabetes in view of it resulting in amputation and mortality ${ }^{[11]}$. Some of the known factors leading to diabetic foot amputation are ulceration, infection, neuropathy, ischemia, deformities etc. ${ }^{[2]}$.

It is well known that treatment of diabetic foot and amputation are costly ${ }^{[11]}$. In developing countries like India, patients affected with diabetic foot complications spend $32.3 \%$ of their income towards its treatment ${ }^{[12]}$.

Often over years, it is observed that most researchers have viewed Diabetic foot as "Diabetic foot ulcers" very frequently. Various studies have been done through Wagner's and University of Texas classification which were meant only for ulcers which is a focal entity ${ }^{[4,13]}$.

Recently, a new simple descriptive classification for diabetic foot was proposed that looked diabetic foot beyond ulcers and it included most lesion in diabetic foot seen universally ${ }^{[13,14]}$. In Kalaivani et al. series, it was seen that $91.06 \%$ of patients who were treated for diabetic foot as inpatients had type 1 diabetic foot complications with wet gangrene being the commonest lesion affecting 35.75 of the patients ${ }^{[14]}$. In this study also, type 1 diabetic foot complications accounted for $76.6 \%$ of the cases and wet gangrene was the commonest pathological lesion affecting $40 \%$ of the patients. Type 1 diabetic foot complications are often acute complications requiring intravenous antibiotics and urgent surgical intervention. It is evident in this study where $90 \%$ of patients underwent emergency surgeries with majority of them being operated within 24 hours of admission especially in evening time of the day.

It was often stated that diabetic foot and amputation were most of the time left to the junior most member of the surgical team who may have little experience especially in amputation ${ }^{[15]}$. Astonishingly, even in our study, majority of the cases [86.7\% were operated by Postgraduate trainee/senior resident who are the junior most member of the team. No surgeries were performed by any senior faculty in this study.

In Kalaivani et al. series ${ }^{[14]}$, debridement was the most common surgical procedure [53.66\%] followed by the toe amputation [25.20\%]. In this study, toe amputation was the commonest surgical procedure being done in $43.4 \%$. There was one mortality in this study.

\section{Conclusion}

Diabetic foot is a neglected entity both by patients and health care professionals leading to increase morbidity and amputations. Our study shows that type 1 diabetic foot complications are the commonest cause of hospitalization. Wet gangrene was the commonest pathological lesion in this study and toe amputation was the commonest surgical procedure done. Most surgeries were done as emergency and majority were done by the junior most team members. Further, only $26.6 \%$ of patients had their foot sensation being evaluated and only $20 \%$ of them had the contra lateral limb being examined. Only $8.3 \%$ of them received some offloading advice. Our study also showed a lower prevalence of ischemia which affected $6.67 \%$ of the cases and around $10 \%$ of patients had underlying osteomyelitis.

\section{Acknowledgement}

Authors would like to thank Dr K.P. Suresh, Scientist (Biostatistics), National Institute of Veterinary Epidemiology and Disease Informatics (NIVEDI), Bangalore, for reviewing the research methodology and statistical results of the study. We also thank the St John's institutional ethics committee for approving our study.

\section{Funding: None \\ Conflict of interest: None}

\section{References}

1. Singh S, Pai DR, Yuhhui C. Diabetic ulcer Diagnosis and management. Clin Res Foot Ankle. 2013; 1(3):120.

2. Batista F, Magalhaes AA, Gamba M, Nery C, Cardosa C. Ten years of a multidisciplinary diabetic foot team approach in Sao Paulo, Brazil. Diabetic Foot \& Ankle. 2010; 1:5203.

3. Viswanathan V, Madhavan S, Rajasekar S, Chamukuttan S, Ambady R. Amputation prevention initiative in South India. Diabetes Care. 2005; 28:1019-1021.

4. Jain AKC, Viswanath S. Distribution and analysis of diabetic foot. OA Case Reports. 2013; 2(21):117.

5. Chalya PL, Mabula JB, Dass RM. Surgical management of diabetic foot ulcers: A Tanzanian University teaching hospital experience. BMC Research Notes. 2011; 4:365.

6. Jain AKC, Joshi S. Diabetic foot classifications: Review of 
literature. Medicine Science. 2013; 2(3):715-21.

7. Rosner B. In: Fundamentals of Biostatistics, 5 th Edition, Duxbury, 2000.

8. Riffenburg RH. In: Statistics in Medicine, 2nd Edition, Academic press, 2005.

9. Rao PSSS, Richard J. In: An Introduction to Biostatistics, A manual for students in health sciences, New Delhi: Prentice hall of India. 4th Edition, 2006.

10. Suresh KP, Chandrasekhar S. Sample Size estimation and Power analysis for Clinical research studies. Journal Human Reproduction Science. 2012; 5(1):7-13.

11. Burakowska AK, Dziemidok P. Diabetic foot- the need for comprehensive multidisciplinary approach. Ann Agri Environ Med. 2011; 18(2):314-317.

12. Viswanathan V, Thomas $\mathrm{N}$, Tandon $\mathrm{N}$ et al. Profile of diabetic foot complications and its associated complications a multicentric study from India. J Assoc. Physicians India. 2005; 53:933-6.

13. Jain AKC. A new classification of diabetic foot complications: a simple and effective teaching tool. J Diab Foot Comp. 2012; 4(1):1-5.

14. Kalaivani V. Evaluation of diabetic foot complication according to Amit Jain's classification. JCDR. 2014; 8(12):7-9.

15. Chalya PL, Mabula JB, Dass RM et al. Major limb amputations. A tertiary hospital experience in northwestern Tanzania. JOSR. 2012; 7:18. 